\title{
Voting Power and Decision Making in Environmental Committees: the Case of French Water Agencies
}

\author{
Vera Zaporozhets
}

September 2015

\begin{abstract}
I employ different concepts of voting power to analyze how the composition of environmental committees and voting rules relate to the voting power of different decision makers in different voting situations. I demonstrate the use of the concepts on data for French river basin committees over the period 1987-2007. In the second part of the paper I discuss how the existing tools and methods can be adapted to examine the problem of fair representation of different interests within environmental committees. The analysis brings relevant insights to the recent water policy debates in France.
\end{abstract}

Key words: water policy design, collective decision making, voting, power indices

\section{Corresponding author at:}

Toulouse School of Economics (LERNA, INRA)

Manufacture des Tabacs, Bât. S

21 Allée de Brienne

31015 Toulouse cedex 6

France

e-mail: vzaporoz@toulouse.inra.fr

phone: +33561635770

fax: +33561128520 


\section{Introduction}

Environmental policies are often negotiated by special environmental committees that involve representatives from several stakeholder groups with divergent interests. This raises several important questions related to the relationship between the design of the decision making process and the effectiveness with which participating stakeholders can pursue their individual interests [18]. To what extent is a given policy maker able to influence the outcome? How is it possible to assess whether or not the interests of different stakeholder groups are fairly represented? How should a committee be designed to have a fair representation of different interests? In this paper I address these questions in the context of water policy in France.

Water Agencies (WAs) are important water policy institutions in many countries, including France. The overal purpose of WAs is to protect water against any action which can deteriorate its quality and quantity. The main focus of current policy is on reaching an adequate ecological and chemical state of river basin resources while maintaining a balance between available water resources and water needs. In practice, this translates into a set of practical objectives, such as the reduction of the impact of human activities on aquatic ecosystems, maintaining the natural processes of aquatic ecosystems, promoting the quantitative management of river streams - in particular during the summer - managing ground water resources in a sustainable manner, improving the quality of drinking water, etc.

Since the middle of 1960s, the French water policy has relied on the principle of decentralized management of the water resource by river basin. In each of the six French WAs, there is a River Basin Committee (RBC) acting as a "water parliament". Consisting of elected members of local and parliamentary chambers, water users' representatives and the public administration, the RBCs are responsible for specifying the environmental objectives of the river basin through voting on different issues.

The focus of this research is the decision making process within environmental committees. The main goals are to synthesize a number of tools and methods from different fields (such as political science, welfare economics and game theory), and to show how they can be adapted and applied to the particular case of the French RBCs. Specifically, I analyze how the composition of the committee and the voting rules relate to the voting power of different decision makers in different types of voting situations. I also discuss the problem of fair representation of different interests within the environmental committees. I believe this analysis may provide relevant insights to the recent policy debates related to water policy in France.

The traditional power measures, such as the Shapley-Shubik index [36] and the Banzhaf index $[34,4]$, have been widely discussed and applied to analyze many voting institutions, such as the EU 
Council of Ministers [22, 32, 33, 15, 8], the United States Legislative system [37, 14], and the Canadian Constitutional Amendment Scheme [37]. The Banzhaf index has been also used to study the design of voting bodies in the EU, US, or IMF [5, 15, 16, 19, 24, 28]. To the best of my knowledge, to date no one has used the concepts of voting power to examine these issues in the context of environmental committees in general, and the French RBCs in particular.

In this paper I apply different power measures traditionally used in the literature, as well as some lesser known measures in this context, in order to analyze the power distribution in two types of voting situations. The first type is the binary setting, in which a decision maker can vote either "yes" or "no", such as in a decision whether or not to construct a dam. However, not all voting situations can be classified as binary, as in, for example, the surplus distribution between stakeholders. I consider such "distributive issues" as a second type of voting situation. One of the examples of a distributive situation is the funding of local projects by the RBC through subsidies. The main difference with the binary setting is that in a distributive setting the set of alternatives is a simplex. Additionally, in the context of the RBCs, in the distributive situations three water users (domestic, industrial and agricultural) usually benefit from the surplus distribution, while other decision makers also vote on the decision. In contrast, there are may be more beneficiaries in the binary situations.

In the binary setting, I use the Banzhaf and the Shapley-Shubik indices that are well adapted for this situation. They measure the probability of a voter to cast a decisive vote. In the context of the distributive situations, the Shapley-Shubik index has also been shown to be an appropriate power measure [14]. It evaluates a voter's expected relative share in a fixed budget. Apart from the ShapleyShubik index, I introduce two other measures of power suitable for analyzing distributive situations. The first is the nucleolus, which is not well known in this context but is becoming more popular, as it can be a good alternative to the Shapley-Shubik index [31, 25, 17]. Another power measure applied in the numerical analysis is derived as the vector of the unique expected equilibrium payoffs from a well known legislative bargaining game [7]. Interestingly, under some conditions it coincides with the nucleolus [29].

In the second part of the paper, I employ power measures to investigate how to design an RBC with a fair representation of different interests. A similar question has been already addressed in the literature in the context of international committees, but mostly under the binary setting. ${ }^{1}$ One of the common approaches is the utilitarian one ${ }^{2}$ that seeks to maximize the total utility of all citizens. Another is the egalitarian approach that seeks to equalize the power of all citizens as measured by the Banzhaf index. Felsenthal and Machover [14] adopt the egalitarian approach and show that the

\footnotetext{
${ }^{1}$ Le Breton et al. [25] is an exception.

${ }^{2}$ See for example, [6], [9] and [10].
} 
optimal weights should be chosen in such a way that each country's Banzhaf index is proportional to the square root of its population size (Penrose's rule [34]). By comparing the Banzhaf index and the square root of the population, they show that larger member states in the EU tend to have too little power, while the smaller ones have too much power. Algaba et al. [1] apply this theory to analyze the power of the European citizens for 25 and 27 countries. Le Breton et al. [25] also follow the egalitarian approach, however they use the distributive setting with the nucleolus as the power measure. In order to investigate this question for the French RBCs, I apply three different power measures suitable for the distributive setting and implement both aforementioned principles. This analysis may provide useful tools for checking the recent conclusion of the French audit office that the RBCs' composition is imbalanced in the sense that the agricultural users have a "quasi-monopoly" [12].

The paper is structured as follows. In Section 2, the organization and the functioning of WAs in France are briefly described. Section 3 provides a descriptive analysis of power for different groups participating in the decision making process related to the water policy. In the first part, I focus on the Banzhaf and the Shapley-Shubik indices to analyze the binary setting. As the analysis demonstrates, in general, the two indices give very close predictions. Then, following [37], I describe possible modifications of the classical indices which may be more applicable in the few cases where the Banzhaf and the Shapley-Shubik indices produce significantly different results. In the second part, I consider distributive situations and compare the performance of the three power measures adapted to the analysis. Additionally, I characterize the conditions under which all three produce the same predictions. In Section 4, I address the issue of the optimal RBC design under the distributive setting, and provide an illustration on the data for the Adour-Garonne Water Agency. Finally, Section 5 provides a summary of the main findings and some policy implications.

\section{French River Basin Committees}

The French WAs were created in 1966, following the first Water Act of 1964 which institutionalized a decentralized water management system at the hydro-geographical level of the river basin. This system has been reinforced by the subsequent Water Acts of $1992^{3}$ and 2006. ${ }^{4}$ The six WAs (Adour-Garonne,

\footnotetext{
${ }^{3}$ The Water Act of January 2, 1992 instituted the principles and tools of integrated water management by the RB. These new tools are the SDAGE (Schémas Directeurs d'Aménagement et de Gestion des Eaux) and the SAGE (Schémas d'Aménagement et de Gestion des Eaux).

${ }^{4}$ The reform of 2006 was devoted to making the system compliant with the Constitution, by reinforcing the role of the RBC, while maintaining control from the State. The goal of the reform was also to improve operational efficiency and to provide enough flexibility in the determination of taxes.
} 
Artois-Picardie, Loire-Bretagne, Rhin-Meuse, Rhône-Méditerranée-Corse and Seine-Normandie) are public administrative establishments under the supervision of two ministries: the Ministry of the Environment and the Ministry of Finance.

WAs participate at each river basin level in national and the European water policies by developing a strategy originating from an overall view of water issues. WAs contribute to reaching an adequate state for water bodies by reducing the impact of human activities, preserving water resources and by satisfying user needs by balancing water resources and rational water use.

Often presented as "water parliaments", RBCs perform several functions. They participate in the design and adoption of multi-year intervention programmes, they determine the major priorities of the intervention policies of the WAs, and they vote on the tax basis and emission tax rates and on the general conditions for attribution of subsidies to water related projects. ${ }^{5}$ The Executive Board first constructs and then submits a proposal to the RBC for approval. The decisions are taken by majority rule, i.e., approval by at least half the participants is necessary to pass a proposal. In what follows, I assume $100 \%$ participation, however some RBCs have explicit quorum requirements.

Each RBC has three bodies: local elected persons, water users (agriculture, industry, domestic water users) and representatives of the State (administration). Each body elects the administrators of the WA from among its members. The government determines the number of Basin Committee members, including the representation of each category of users (agriculture, tourism, industry, etc.). Representatives of the State from various ministries as well as from the State prefectures are also included. For example, in the Adour-Garonne RBC in 2012 there were 135 members divided into three bodies: the first body of 54 members representing the local communities; the second body of 54 members representing users and professional bodies; and the third body of 27 members representing the State and public boards. The first body is composed of representatives from the regions, the large and the small municipalities (with a qualification for the municipalities located in either mountain areas or seaside areas). The second body has nine representatives from agriculture, 27 representatives from industry and 18 representatives from different associations (e.g., consumers, environmentalists), regional social and economic councils and groups of experts.

The composition of the RBCs depends on the geographical range of the basin with a minimum of 58 members in Rhin-Meuse RBC in the period 1993-1998 and a maximum of 187 members in SeineNormandie in the period 2005-2007. The proportion of representatives for local communities, regions and districts is significant, compared to the representatives of water users. Representatives from

\footnotetext{
${ }^{5}$ There are several commissions within an RBC, which are delegated by the Executive Board of WAs to work on important projects, for example, the Subsidy Commission.
} 
the agricultural sector are typically more numerous in the RBCs characterized by higher agricultural activity, as in Adour-Garonne and Loire-Bretagne. Representatives of the State are in the minority while the number of local elected persons is greater than one third on average. Representatives of users and socio-professional groups have the majority. In 1999, the composition of the RBCs and Executive Boards in all WAs was renewed in order to reinforce representation of urban and rural communities, consumer associations, environmental associations, agriculture, and a new representative for smalland medium-sized industries. There are now about $40 \%$ of elected members for local communities, $40 \%$ for water user representatives, and $20 \%$ for representatives of the State.

\section{Descriptive analysis of power}

\subsection{Binary Issues: The Banzhaf and the Shapley-Shubik power indices}

In this subsection, we consider binary "yes" / "no" decisions by the committee. For simplicity, we assume that amendments to the proposal are not possible. In this setting, a priori power of a voter is usually measured by the probability of the voter being pivotal. In this context, the two classical voting power measures - namely the Banzhaf and the Shapley-Shubik power indices - are most often used in the literature. First, I recall the formal definitions, and then provide numerical results for the two indices applied to the six French RBCs in the period 1987-2007.

In what follows, $N$ denotes a set of the $n$ members of an RBC. We also define a set of winning coalitions $\mathcal{W}$ : a collection of subsets of $N$ with the following properties:

1) $\emptyset \notin \mathcal{W}$;

2) $N \in \mathcal{W}$;

3) if $S \in \mathcal{W}$ and $T \supset S$ then $T \in \mathcal{W}$ (monotonicity).

The interpretation of the set $\mathcal{W}$ as follows: If $S$ is a set of members voting in favour of a particular decision then the decision is accepted if $S \in \mathcal{W}$ and it fails if $S \notin \mathcal{W}$. Sets that do not belong to $\mathcal{W}$ are called losing coalitions. A pair $(N, \mathcal{W})$ is called a simple game, and fully describes an RBC.

The Shapley-Shubik index (SSI) for a simple game $(N, \mathcal{W})$ is defined as follows. The players vote in a specific order and as a majority is reached the proposal is accepted. The voter whose participation turns the existing coalition from a losing into a winning one is called critical for that ordering. The critical voter is assumed to get the credit for having passed the bill. The SSI is then determined through the assumption of a random voting order:

$$
\phi_{i}=\frac{\text { number of orderings in which } i \text { is critical }}{\text { total number of orderings }} .
$$


One may notice that $\sum_{i=1}^{n} \phi_{i}=1$, i.e., the vector $\phi=\left(\phi_{1}, \phi_{2}, \ldots, \phi_{n}\right)$, is normalized.

The Banzhaf index of a simple game $(N, \mathcal{W})$ is introduced in a different way. One defines a swing for any player $i$ as a winning coalition $S$ containing $i$ and such that $i^{\prime}$ s departure from $S$ would change coalition $S$ from winning to losing. Let us define:

$$
\beta_{i}^{\prime}=\frac{\text { number of swings for } i}{2^{n-1}} .
$$

Vector $\beta^{\prime}=\left(\beta_{1}^{\prime}, \beta_{2}^{\prime}, \ldots, \beta_{n}^{\prime}\right)$ is called absolute Banzhaf power and, in fact, is not normalized. The normalized version of this measure (the Banzhaf power index $(\mathrm{Bz})$ ), is given by:

$$
\beta_{i}=\frac{\beta_{i}^{\prime}}{\sum_{i=1}^{n} \beta_{i}^{\prime}}
$$

In what follows, I focus on the power analysis for the six French RBCs in the period 1987-2007. The voting situations in RBCs can be represented through weighted majority games. The game $(N, \mathcal{W})$ is said to be a weighted majority game if there exists an $n$-tuple $\omega=\left(\omega_{1}, \ldots, \omega_{n}\right)$ of non-negative weights with $\omega_{1}+\omega_{2}+\ldots+\omega_{n}=1$ and a non-negative quota $q$ such that any $S \in \mathcal{W}$, if and only if the total weight of the players in $S$ exceeds the quota $q$, i.e., $\sum_{i \in S} \omega_{i} \geq q$. The pair $[q ; \omega]$ is called a representation of the game $(N, \mathcal{W})$. In order to run the calculations, it is necessary to have information on the number of representatives in the committees (provided in the Appendix) and the quota. Given that the decisions are taken by the majority rule, the quota is calculated as $q=\left\lfloor\frac{\sum_{i=1}^{n} q_{i}}{2}\right\rfloor .6$

Table 6 in the Appendix provide calculations for the distribution of power among different decision makers in the Adour-Garonne RBC in the period $1987-2007 .{ }^{7}$ The results indicate that the Bz and the SSI give very close predictions in most cases. Not surprisingly, districts have a very high voting power, around 30\%, while industrial users have around 15\%. There are also many small groups with relatively low values of the $\mathrm{Bz}$ and the SSI.

It is important to distinguish voting weight from power, as in general the voting power need not be proportional to voting weights. ${ }^{8}$ However, in our case (see Table 6), the power indices for the RBCs are almost proportional to the weights. Here we deal with a situation where there is a large number of players and none of them is dominant enough. It seems that in this case Penrose's approximation ${ }^{9}$

\footnotetext{
${ }^{6}$ For any real number $x,\lfloor x\rfloor$ denotes the smallest integer greater than $x$.

${ }^{7} \mathrm{I}$ use computer software for the voting power analysis available at http://homepages.warwick.ac.uk/ ${ }^{\sim}$ ecaae/ (accessed February 2015). Calculations for other RBCs are available in the earlier version of the paper.

${ }^{8}$ A striking example is the EU Council of Ministers in the period 1958-1972: even though Luxembourg held one vote, formally it was never able to make any difference in the voting process.

${ }^{9}$ See, for example, [23].
} 
works well. It states that voting power tends to become proportional to voting weights as the number of voters increases, provided that the distribution of voting weights is not "too unequal". In fact, when the players are put into a smaller number of blocks, the power indices are no longer proportional to the weights. ${ }^{10}$

There are some intuitive properties that the Bz and the SSI satisfy. For example, both indices respect monotonicity. Whenever representative $i$ has more votes than representative $j$, the voting power of $i$ is higher than the power of $j$. However, the relation of voting weights to the power is not as straightforward. One may think that it is possible to decrease a voter's voting weight within a voting body and at the same time increase his/her power, however this is not always the case. It is called the "paradox of redistribution" [14]. The idea is that there is a voter "donating" some weight to another voter, so that the donor loses weight and the recipient gains some weights, while the total weight stays the same. The paradox of redistribution states that a donor can gain power or a recipient can lose power. This is the case for industry in the Adour-Garonne RBC (see Table 7 in the Appendix): the relative number of votes for professional bodies as well as for rural communities has dropped from the period 1993-1998 to the period 1999-2004. However, both the Bz and the SSI show an increase in power.

\subsubsection{Extensions}

In this section I discuss possible modifications of the Bz and the SSI which may be more applicable when the interests of some groups are correlated.

Straffin [37] has proved that the Bz and the SSI can be derived from the same basic probabilistic model under different assumptions regarding voting behaviour. The Bz is obtained under the assumption that the voters vote completely independently (independence assumption). In contrast, the SSI is obtained under the assumption that the voters have some common standards or values (homogeneity assumption).

Suppose that $X_{i}$ is a random variable for each $i=1 \ldots n$. It takes value 1 if player $i$ votes "yes" on the given proposal, and 0 if player $i$ votes "no". Let us denote by $p=\left(p_{1}, \ldots, p_{n}\right)$, the vector with the components $p_{i} \in[0,1]$ being the probability that $X_{i}=1$. For different proposals, the components $p_{i}$ are selected from some probability distribution on $[0,1]$. The Independence Assumption states that the $p_{i}$ 's are selected independently from the uniform distribution on $[0,1]$. This assumption implies that each player will vote in favour of any decision with the probability $1 / 2$. The Homogeneity Assumption states that a number $p$ is selected from the uniform distribution on $[0,1]$, and $p_{i}=p$ for all $i$. Straffin

\footnotetext{
${ }^{10}$ See discussion in the following subsection and Table 7 for the Adour-Garonne RBC in the Appendix.
} 
[37] proves that the answer to the question, "What is the probability that the bill supported by player $i$ pass?" is given by the absolute Banzhaf measure $\beta_{i}^{\prime}$ under the independence assumption, and is given by the SSI under the homogeneity assumption.

One may argue that the assumption of the uniform distribution is restrictive. Thus, Berg [11] proposes to introduce a general probability density function $f$ defined on the interval $[0,1]$. Then, the modified homogeneity assumption states that a number $p$ is drawn according to the distribution $f$ on $[0,1]$, and $p_{i}=p$ for all $i$. In the case of beta distribution:

$$
f(p)=\frac{\Gamma(2 \alpha)}{(\Gamma(\alpha))^{2}} p^{\alpha}(1-p)^{\alpha}
$$

where parameter $\alpha>0$ and $\Gamma$ is gamma function. ${ }^{11}$ One may calculate:

$$
\operatorname{Pr}\left(X_{i}=1 \text { and } X_{j}=1\right)=\int_{0}^{1} p^{2} f(p) d p=\frac{1}{4}+\frac{1}{4(2 \alpha+1)} .
$$

Then the covariance is:

$$
\operatorname{cov}\left(X_{i}, X_{j}\right)=\frac{1}{4(2 \alpha+1)}
$$

and the correlation coefficient between the votes of two voters is:

$$
\rho=\frac{1}{2 \alpha+1}
$$

When $\alpha \rightarrow 0$ one gets $\rho \rightarrow 1$ (perfect positive correlation) and when $\alpha \rightarrow \infty$ one gets $\rho \rightarrow 0$ (independence).

When $\rho=1$ we get the block model [14], in which some representatives always vote in the same way (form blocks). In the Appendix there is an example of gathering different representatives into 11 blocks according to the similarity of their preferences. ${ }^{12}$ The first three categories correspond to water users (those paying emission and water use taxes, and receiving subsidies from the WA), while other categories are special-interest groups, ministries and administration. The values for the SSI and the Bz for the Adour-Garonne RBC in such a case are shown in Table 7 (see Appendix).

One may think that when assigning representatives in the same block, their total power should be at least as great as the sum of the power assigned to the same representatives in the original setting before the formation of the block. While it may seem intuitive, in general this property does not hold. It is called the paradox of large size or the superadditivity property [14].

\footnotetext{
${ }^{11}$ The case $\alpha=1$ represents the uniform distribution.

${ }^{12}$ For a more accurate analysis it is neccessary to have data on the actual votes of the different representatives in the six RBCs, which is not available.
} 


\subsection{Distributive Issues}

The analysis of distributive issues in RBCs - such as taxes and subsidies - has some specificities. There are usually three groups, i.e., domestic water users, industrial water users and the farmers contributing to the budget by paying different taxes. They may benefit from the redistribution by receiving subsidies in order to finance different projects. However, all members of the committee including representatives of the administration - participate in the decision making process. The representatives of water users in the committee are assumed to be selfish, i.e., driven exclusively by their own shares in the proposal. In contrast, the preferences of the other committee members can possibly aggregate the welfare of the three categories of users.

Here, I impose a simplifying assumption that each representative of the administration acts on behalf of a single group of users. Formally, the water users are indexed by $i=1,2,3$ and the representatives of the administration by $j=4, \ldots, n$. Let us denote by $\omega_{i}$ the voting weight (number of representatives) of sector $i$ for all $i=1, \ldots, 3$. All other voters have a weight equal to 1 . Let us denote by $m_{i}$ the number of representatives in the set $\{4, \ldots, n\}$ acting on behalf of user $i$. We have:

$$
\sum_{i=1}^{3} m_{i}=n-3 .
$$

The group of voters voting on behalf of the group $i=1 \ldots 3$ has a weight equal to:

$$
q_{i}=\omega_{i}+m_{i}
$$

We have obtained a new weighted majority game with three players $\left[q ; q_{1}, q_{2}, q_{3}\right]$, where the quota $q$ is the same as before. In fact, for three groups there are very few possible games. Hereafter I will consider two classes of games. The first, $\mathcal{K}_{1}$, is the class consisting of weighted majority games which are monotonic, ${ }^{13}$ proper $^{14}$ and directed. ${ }^{15}$ Following [25] for three players there are five possible games in class $\mathcal{K}_{1}$ :

1) $[1 ; 1,0,0]$ in which player 1 is a dictator,

2) $[3 ; 2,1,1]$ in which player 1 is a veto player $^{16}$ but not a dictator,

3) $[2 ; 1,1,0]$ in which players 1 and 2 are veto players,

4) $[3 ; 1,1,1]$ in which all three players are veto players,

5) $[2 ; 1,1,1]$ which is the simple majority game with no veto players.

The second class, $\mathcal{K}_{2}$, is the class of weighted majority games which are strong. ${ }^{17}$ In the case of

\footnotetext{
${ }^{13}$ Adding players cannot turn a winning coalition into a losing one.

${ }^{14}$ No two disjoint coalitions can be winning.

${ }^{15}$ Players can be unambiguously ranked in order of desirability.

${ }^{16}$ A player that belongs to all minimal winning coalitions is called a veto player.

${ }^{17}$ For any coalition $S \notin \mathcal{W}$ coalition $N \backslash S \in \mathcal{W}$.
} 
three players, $\mathcal{K}_{2}$ consists of only two possible games: the simple majority game and the dictator game. As one may confirm, a weighted majority game with a quota of $50 \%$ of the total votes (as in the French RBC) belongs to $\mathcal{K}_{2}$.

\section{Example: The Adour-Garonne RBC, 1987-2007}

In this example, I group the decision makers in the Adour-Garonne RBC into three groups by attributing the votes of state representatives and other non-users to the three water user groups following (1). The above remark implies that as a result, one may get either the simple majority or the dictatorial game.

To proceed in a rigorous manner, one would need the data on actual votes in the committee, which are not available. Instead, I assume that all of the representatives of the rural communities, the Ministries of Agriculture, Land Development and Rural Affairs vote in line with the farmers. The representatives of the associations of domestic water users, environmental organizations, fishery, water suppliers, tourism, and the Ministries of Health, the Environment and the Interior all cast their votes on behalf of domestic water users. The representatives of the Ministry of Industry have their votes in line with the industrial users. Other RBC members who are not water users split their votes equally between the three groups. As a result, one gets the distribution of seats between the three user groups, as presented in Table 1.

\begin{tabular}{lllll}
\hline \multicolumn{6}{l}{ Table 1 Distribution of Representatives in the } & Adour-Garonne RBC, 1987-2007 \\
\hline & $1987-1992$ & $1993-1998$ & $1999-2004$ & $2005-2007$ \\
Agriculture & 22.67 & 21.33 & 25.67 & 24 \\
Industry\&Energy & 27.67 & 27.33 & 28.67 & 29 \\
Domestic & 33.67 & 32.33 & 43.67 & 44 \\
Total & 84 & 81 & 98 & 97 \\
Quota & 43 & 41 & 50 & 49 \\
\hline
\end{tabular}

Table 1 demonstrates that for all four periods, the distribution of seats and the quota correspond to the simple majority game $[2 ; 1,1,1]$.

The most famous power measure applied in the distributive situations is the SSI. ${ }^{18}$ Thus, Felsenthal and Machover [14] argue that the SSI is a measure of "P-power", where P stands for "purse", and evaluates a voter's expected relative share in a fixed budget. In addition, I describe below two alternative power measures.

\footnotetext{
${ }^{18}$ For the definitions and the properties see, for example, [14] and [21], among others.
} 


\subsubsection{The Nucleolus}

The nucleolus (Nucl) is a solution concept for cooperative games, first formulated in [35]. As it is argued in $[29,25,17]$, the nucleolus is a measure suitable for analyzing the bargaining over a fixed budget, and can be a good alternative to the SSI.

Mashler et al. [26] provide the following intuitive meaning of the nucleolus. Suppose there is an arbitrator who helps the players decide on the allocation of the common budget. The excess of a coalition (the gain/loss that the members of the coalition have if they depart from it) is a measure of dissatisfaction. The coalitions with a negative excess do not want to defect, and the higher the excess of the coalition, the higher the coalition dissatisfaction. Thus, the arbitrator will look for payoffs in which the highest excess is as low as possible. If there are several such payoffs, he will proceed in a recursive manner: he chooses the outcomes for which the second highest excess is minimal, and so on. The nucleolus recursively minimizes the "dissatisfaction" of the worst treated coalitions. The formal definition of the nucleolus is provided in [26], among others.

It appears that the nucleolus of a game in coalitional form exists and is unique. If the core is not empty, the nucleolus is in the core. Like the Shapley value, the nucleolus can be obtained as the unique value satisfying a set of axioms [27].

\subsubsection{Bargaining and Power}

In this section, we describe the power of the players as the expected equilibrium payoffs from a popular legislative bargaining game [7] adapted for our specific setting. As previously discussed, the main specificity here is that all of the decision makers in the RBC participate in the decision regarding the distribution of the surplus, however, only three water user groups actually benefit from the final distribution.

The bargaining proceeds as follows. At every round $t=1,2, \ldots$ Nature selects a random proposer: player $j$ is selected with probability $p_{j}$ with $j=1, \ldots, n$. This player proposes a distribution of the budget $\left(x_{1}, x_{2}, x_{3}\right)$ with $x_{i} \geq 0$ for all $i=1,2,3$ and $\sum_{i=1}^{3} x_{i}=1$. Due to our assumption regarding the behaviour of the representatives from the administration, the probability of player $i=1,2,3$ being selected as a proposer is equal to $\widehat{p}_{i}=p_{i}+\sum_{k \in M_{i}} p_{k}$. The proposal is voted upon immediately according to the voting rule represented by a voting game $\left[q ; q_{1}, q_{2}, q_{3}\right]$ as derived above. If the coalition of voters in favour of the proposal is winning, the proposal is implemented and the game ends; otherwise the game proceeds to the next period in which Nature selects a new proposer. Players are risk neutral and discount future payoffs by a factor $\delta_{j} \in[0,1)$. A (pure) strategy for player $j$ is a sequence $\sigma_{j}=\left(\sigma_{j}^{t}\right)_{t=1}^{\infty}$, where $\sigma_{j}^{t}$, the $t$ th round strategy of player $j$, prescribes: 


\section{A proposal $x$,}

2. A response function assigning "yes" or "no" to all possible proposals by the other players.

The solution concept is the stationary subgame perfect equilibrium (SSPE). ${ }^{19}$ Banks and Duggan [3] have shown that an SSPE always exists in this type of bargaining model. In addition, Eraslan [13] has shown that all SSPE lead to the same expected equilibrium payoffs. ${ }^{20}$

Following [30] and [25] we consider a specific case where $\delta \rightarrow 1$ and equal recognition probabilities. In this case, we refer to the unique vector of expected equilibrium payoffs such as the "Baron-Ferejohn" measure of power attached to the simple game $(N, \mathcal{W})$, and denote it by $\mathrm{BF}$.

Table 2 presents the values for the SSI, the nucleolus and the BF for the case of equal recognition probabilities, i.e., $\widehat{p}_{i}=1 / 3$ for $i=1 \ldots 3$. Interestingly, the Nucl and the BF give the same predictions for all five games in $\mathcal{K}_{1}$. One may notice that in the presence of veto players, the two indices - the Nucl and the BF - attribute all power to the veto players and leave the other players with no power. Moreover, the power is equally shared between the veto players if there are several of them. The Nucl and the BF disagree with the SSI only in the case of the veto game $[3 ; 2,1,1]$.

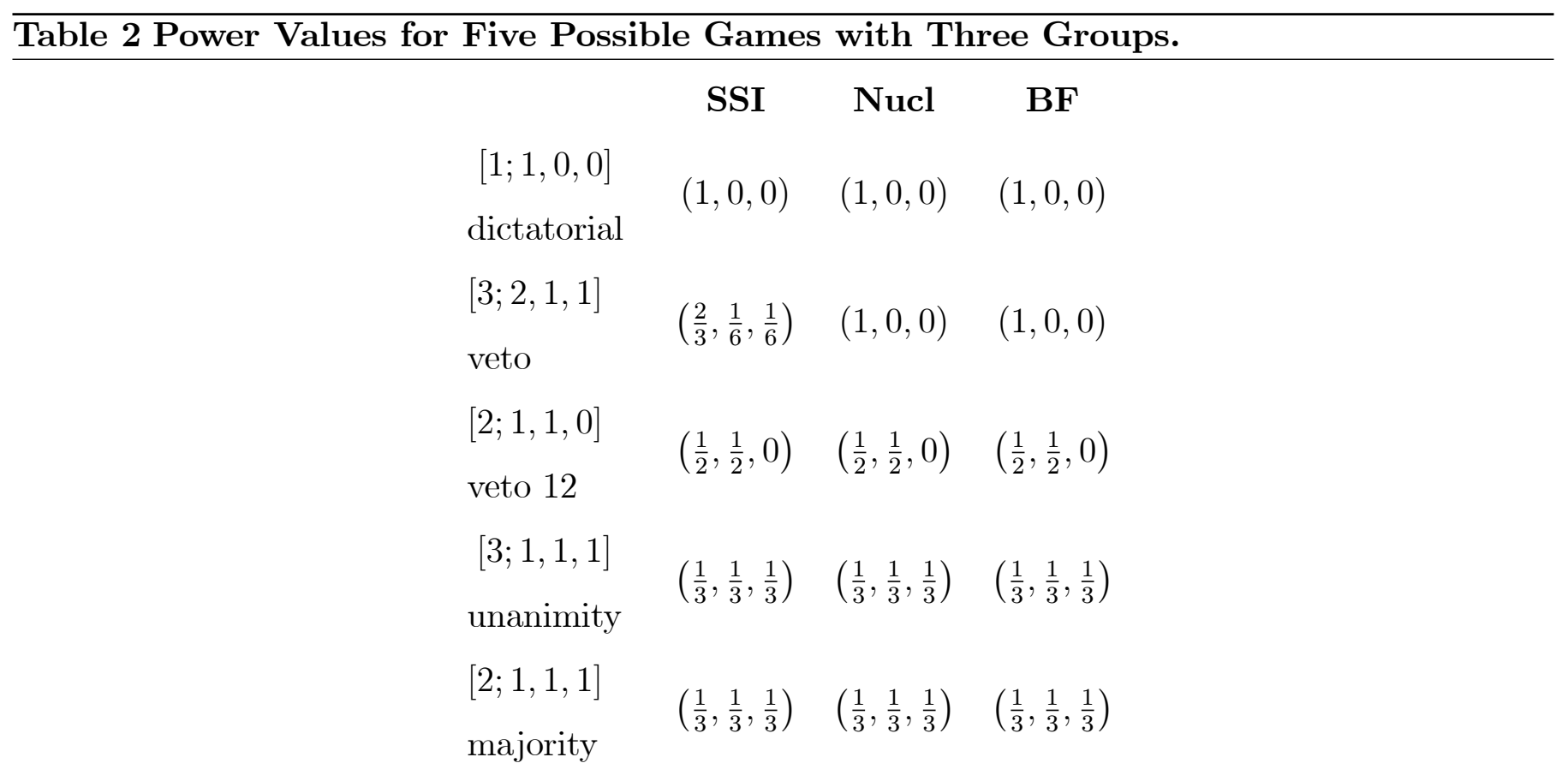

One may notice that the example for the Adour-Garonne RBC corresponds to the last row in the table, i.e., the three indices suggest equal distribution of power for the three water user groups.

\footnotetext{
${ }^{19}$ Stationarity requires that players follow the same strategy at every round $t$ regardless of past offers and responses to past offers.

${ }^{20}$ Moreover, Montero [29] has analyzed the above bargaining game in the case where $\delta_{i}=\delta<1$ for all $i=1, \ldots, n$. She shows that if the vector $p$ coincides with the nucleolus, then $p$ is the unique vector of equilibrium payoffs.
} 
I characterize the set of possible weights $q_{1}, q_{2}, q_{3}$ for which the three indices disagree. First, the sets $M_{i}$ are not known exactly, however, due to equality (1), the following inequalities should be satisfied:

$$
q_{i} \geq \omega_{i} \text { for } i=1 \ldots 3
$$

The total number of representatives should stay the same:

$$
\sum_{i=1}^{3} q_{i}=\sum_{i=1}^{3} \omega_{i}+n-3 .
$$

The disagreement appears in the situation with one vetoer. Suppose, it is player 1. Then, we get additional set of inequalities:

$$
\begin{aligned}
& q_{1}+q_{2} \geq q \\
& q_{1}+q_{3} \geq q \\
& q_{2}+q_{3}<q .
\end{aligned}
$$

Similar inequalities hold if player 2 or 3 is a vetoer.

\section{Institutional design}

In this section, I apply different power measures developed in the previous sections to address the important question of how to design an RBC with a fair representation of different water users' interests. I focus on the distributive setting only, and tackle the problem in two steps. First, I characterize voting rules that satisfy either of the two commonly used fairness principles, i.e., utilitarianism and egalitarianism. The first principle aims to maximize the total sum of voters' utilities, whereas the second seeks to equalize utility levels for equals. Unfortunately, as explained below, it is not always possible to obtain such a first-best rule. Therefore, in the second step, I discuss a way to obtain voting rules that are as close as possible to the first-best rule.

In the following, we compare two situations: the direct committee and the committee of representatives. In the first situation, there are no intermediate voting bodies, and water users represent themselves. We will see that users' preferences play an important role in the design of the voting rule to satisfy either principle. Not surprisingly, if the preferences are homogeneous then the total budget should be distributed equally among all water users. However, the negotiation often takes place across the representatives, and the share obtained by the representatives in the RBC is then divided among the corresponding water users. It is not surprising that in this situation, not only do individual preferences matter but also the number of groups and their sizes. 
As before, let us assume that the water users' groups are labelled by $i=1, \ldots, k$ and their sizes are denoted by $n_{i}$. The total population is $n=\sum_{i=1}^{k} n_{i}$. The utility function of any user in group $i=1, \ldots, k$ is $u_{i}(\cdot)$. The total budget to be distributed is $B$, and the stakes obtained by each group's representatives are $B_{i}, i=1, \ldots, k$ and $\sum_{i=1}^{k} B_{i}=B$.

We assume that in the case of the direct committee, each water user $j$ in group $i$ obtains $\Delta_{i j}$ and:

$$
\sum_{i=1}^{k} \sum_{j=1}^{n_{i}} \Delta_{i j}=B
$$

For the committee of representatives, we assume that there is no bargaining inside the groups, and that the budget obtained is divided equally, i.e., $\Delta_{i j}=\frac{B_{i}}{n_{i}}$.

Let us first consider the utilitarian approach. If the water users represent themselves, i.e., there is a direct committee, we seek a solution for the following maximization problem:

$$
\begin{aligned}
& \max \sum_{i=1}^{k} \sum_{j=1}^{n_{i}} u_{i}\left(\Delta_{i j}\right) \\
& \text { s.t. }(2) .
\end{aligned}
$$

First order conditions imply that:

$$
u_{i}^{\prime}\left(\Delta_{i j}\right)=\lambda, \text { for all } j=1, . ., n_{i} \text { and } i=1, \ldots, k,
$$

where $\lambda$ is the Lagrange multiplier attached to the constraint (2).

If we have a committee of representatives, then we have to maximize:

$$
\begin{aligned}
& \max \sum_{i=1}^{k} n_{i} u_{i}\left(\frac{B_{i}}{n_{i}}\right) \\
& \text { s.t. } \sum_{i=1}^{k} B_{i}=B .
\end{aligned}
$$

From the first order condition, one gets:

$$
u_{i}^{\prime}\left(\frac{B_{i}}{n_{i}}\right)=\mu
$$

where $\mu$ is the Lagrange multiplier attached to the budget balance constraint.

To summarize, for the direct committee egalitarianism suggests equalizing utilities $u_{i}$ at $\Delta_{i j}$, while utilitarianism suggests equalizing marginal utilities $u_{i}^{\prime}$ at the same point, $\Delta_{i j}$. For the committee of representatives, under the egalitarian approach the utility levels $u_{i}\left(\frac{B_{i}}{n_{i}}\right)$ should be equalized, and under utilitarian approach the marginal utilities $u_{i}^{\prime}\left(\frac{B_{i}}{n_{i}}\right)$ should be equalized.

If $u_{i}=u$ for all $i=1, \ldots, k$ then one gets:

$$
\Delta_{i j}=\frac{B}{n} \text { and } B_{i}=\frac{n_{i} B}{n} .
$$


Thus, under the assumption of homogeneous preferences, ${ }^{21}$ both principles suggest that the relative budgets $\frac{B_{i}}{B}$ for the groups $i=1, \ldots, k$ should be equal to their relative sizes $\frac{n_{i}}{n}$.

Hereafter, we assume that each group's budget share $\frac{B_{i}}{B}$ is equal to one of the three power indicesthe SSI, the Nucl and the BF. Suppose that the voting rule in RBC is described by a simple game $(M, \mathcal{W})$, where $M=\{1,2,3\}$ is the set of water users' groups, and $\mathcal{W}$ is the set of the winning coalitions. Vector $\alpha=\left(\alpha_{1}, \alpha_{2}, \alpha_{3}\right)$ denotes the budget shares of the water users representatives measured by the SSI, the Nucl or the BF. Based on our conclusion, the first-best situation is described by the condition that the components of power index $\alpha$ induced by the game $(M, \mathcal{W})$ coincide with $\frac{n_{i}}{n}$.

It is not always possible to obtain the first-best situation, since vector $\alpha$ belongs to a simplex, while the number of possible weighted majority games for each number of players $k$ is finite (for example, for $k=3$, the number of weighted majority games in $\mathcal{K}_{1}$ is 5$)$. Therefore, we try to find simple games from a specified class whose power index is as close as possible to the population shares. Specifically, we would like to design the simple game $(M, \mathcal{W}) \in \mathcal{K}_{1}$ in such a way that the distance between the power index $\alpha$ and the relative sizes is as small as possible. ${ }^{22}$ Following [25], we consider quadratic distance. ${ }^{23}$ Our problem is defined as follows:

$$
\min _{(M, \mathcal{W}) \in \mathcal{K}_{1}} \operatorname{var}(\alpha(M, \mathcal{W}))
$$

and

$$
\operatorname{var}(\alpha(M, \mathcal{W}))=\sum_{i=1}^{3} n_{i}\left[\frac{1}{n}-\frac{\alpha_{i}}{n_{i}}\right]^{2} .
$$

Term $\frac{\alpha_{i}}{n_{i}}$ indicates how much power (according to any of the three power indices) a water user in

\footnotetext{
${ }^{21}$ Of course, in reality the users' preferences are not homogeneous. For example, the utility for user group $i=1,2,3$ can be specified as $u_{i}(x)=u\left(\frac{x}{\theta_{i}}\right)$, where $\theta_{i}$ is a characteristic for group $i$. Then, the egalitarian approach would suggest equalizing $\frac{B_{i}}{\theta_{i} n_{i}}$ across the representatives in the committee, where $B_{i}$ is the budget attributed to group $i$. This leads to the conclusion that the representatives' budgets $B_{i}$ should be proportional to $\theta_{i} n_{i}$ as compared to $n_{i}$ in the case of homogeneous preferences. For the utilitarian approach the conditions for $B_{i}$ are more complicated and without knowing the utility $u$ one cannot be specific, except that $\frac{1}{\theta_{i}} u^{\prime}\left(\frac{B_{i}}{\theta_{i} n_{i}}\right)$ should be equalized across all $i$.

${ }^{22}$ The general problem of finding a voting method which will give a good approximation to the desired powers (known as an inverse problem), has been recently formulated for the Bz by Alon and Edelman [2]. The authors analyze power distributions with most of the power concentrated on the small number of voters. They provide explicit bounds stating that a $\mathrm{Bz}$ vector with weights concentrated on $k<n$ players has to be near the $\mathrm{Bz}$ vector of a game with $n-k$ dummy players. Kurz [20] tightens this bound and obtains similar bounds for several other power indices. To the best of my knowledge, there are no general results on the inverse problem for the Nucl, the SSI or the BF.

${ }^{23}$ Alternatively, it is possible to use other inequality measures, such as the Gini coefficient or the Lorenz curve.
} 
group $i$ gets given specific voting rules. The expression (3) can be simplified into:

$$
\operatorname{var}(\alpha(M, \mathcal{W}))=\sum_{i=1}^{3} \frac{\left(\alpha_{i}\right)^{2}}{n_{i}}-\frac{1}{n} .
$$

Following [25], I illustrate the procedure for solving the problem in the case of three voters:

1. Calculate the power index $\alpha$ for each game in class $\mathcal{K}_{1}$ and find the variance using (4);

2. Choose the game with the minimal variance. ${ }^{24}$

Hereafter, we express the variance in terms of population shares, $\gamma_{i}=\frac{n_{i}}{n}, i=1,2,3$. Without loss of generality, we assume that $\gamma_{1} \geq \gamma_{2} \geq \gamma_{3}$. We denote by:

$$
\begin{aligned}
V_{1} & =\frac{1}{\gamma_{1}}-1, \\
V_{2} & =\frac{1}{4}\left[\frac{1}{\gamma_{1}}+\frac{1}{\gamma_{2}}\right]-1, \\
V_{3} & =\frac{1}{9}\left[\frac{1}{\gamma_{1}}+\frac{1}{\gamma_{2}}+\frac{1}{\gamma_{3}}\right]-1, \\
V_{4} & =\frac{1}{36}\left[\frac{16}{\gamma_{1}}+\frac{1}{\gamma_{2}}+\frac{1}{\gamma_{3}}\right]-1 .
\end{aligned}
$$

The results for three power indices are presented in the Table 3 below.

\section{Table 3 Variances for Five Possible Games with Three Groups}

\section{SSI Nucl and BF}

$\begin{array}{lll}{[1 ; 1,0,0]} & \frac{V_{1}}{n} & \frac{V_{1}}{n} \\ \text { dictatorial } & & \\ {[3 ; 2,1,1]} & \frac{V_{4}}{n} & \frac{V_{1}}{n} \\ \text { veto } & & \\ {[2 ; 1,1,0]} & \frac{V_{2}}{n} & \frac{V_{2}}{n} \\ \text { veto } 12 & & \\ {[3 ; 1,1,1]} & \frac{V_{3}}{n} & \frac{V_{3}}{n} \\ \text { unanimity } & & \\ {[2 ; 1,1,1]} & \frac{V_{3}}{n} & \frac{V_{3}}{n} \\ \text { majority } & & \end{array}$

In Figure 1 we show the values of the two biggest groups' population shares, $\gamma_{1}$ and $\gamma_{2}$, for which each of the five games is optimal under the SSI, the Nucl and the BF.

\footnotetext{
${ }^{24}$ For large committees this method is difficult to implement in practice as the number of possible games grows in an exponential manner [25]. Given the relatively small number of main stakeholders on environmental committees, this method is easy to use.
} 
Figure 1 The optimal rule for three voters under the SSI, the Nucl and the BF
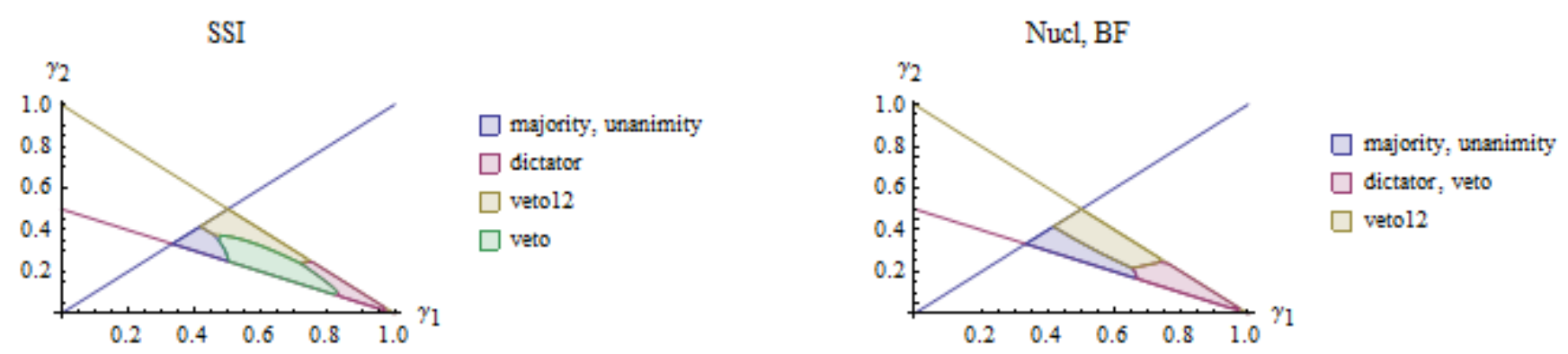

One may notice that the simple majority $([2 ; 1,1,1])$ and unanimity $([3 ; 1,1,1])$ rules can not be distinguished under the three power indices. Not surprisingly, the majority rule is optimal when the three groups are not too different in terms of their population shares. On the contrary, dictatorial rule $([1 ; 1,0,0])$ is optimal in the case where there is a relatively big group. Under the SSI there are four different regions, while under the Nucl and the BF there are only three. The Nucl and the BF cannot distinguish between veto $([3 ; 2,1,1])$ and dictatorial rule. Under the SSI, veto rule is distinguished from other rules.

The following example demonstrates the use of the technique.

\section{Example: The Adour-Garonne RBC, 1987-2007 (continued)}

From the calculations in the previous section we conclude that under the assumptions made, the decision rule operating in the Adour-Garonne $\mathrm{RBC}$ is the simple majority rule. It implies that the three groups have equal voting power according to the SSI, the Nucl and the BF. Hereafter, we will check whether or not the three water user groups are fairly represented in the committee. In order to do so, we check whether or not the three water users groups in the Adour-Garonne river basins are of the same size.

In what follows, the data on the employment in industry and agriculture as well as the total employment in the Adour-Garonne river basin in the period 1989-2006 is used as a proxy for the number of different water users. People working in industry and agriculture are also domestic water users, therefore the number of industrial and agricultural water users is estimated at half of the number of employed people in industry and agriculture respectively. The number of domestic users is calculated as the difference between the total employment and half of people employed both in industry and agriculture. Table 8 in the Appendix presents the population shares for the three water user groups in the Adour-Garonne river basin in 1989-2006 under this assumption. It indicates that the shares for industrial and agricultural users were declining over time whereas the share for domestic users was increasing. The share for domestic water users is always the biggest and the share for 
agriculture is the smallest, while the gap in shares between the domestic water users and the two other groups increases. Thus, the shares for the three groups are far from being equal, and we may conclude that under our specific assumption, the domestic water users are under-represented, and that the two other groups are over-represented.

Following the procedure described above we will identify the optimal decision rule for both scenarios. To do so, we calculate variances according to the formulas from Table 3. In our case $\gamma_{1}, \gamma_{2}$ or $\gamma_{3}$ corresponds to the populational shares for the domestic, industrial or agricultural users respectively. As we have seen, the assumption $\gamma_{1} \geq \gamma_{2} \geq \gamma_{3}$ is satisfied.

In Table 4 below the four variances are calculated.

\section{Table 4 Values of Variance Calculated for Adour-Garonne River Basin, 1989-2006}

\begin{tabular}{c|cccc} 
& $V_{1}$ & $V_{2}$ & $V_{3}$ & $V_{4}$ \\
1989 & 0.165 & 2.128 & 2.477 & 0.355 \\
1990 & 0.162 & 2.140 & 2.559 & 0.374 \\
1991 & 0.156 & 2.210 & 2.661 & 0.397 \\
1992 & 0.152 & 2.286 & 2.744 & 0.416 \\
1993 & 0.146 & 2.382 & 2.877 & 0.447 \\
1994 & 0.142 & 2.443 & 2.993 & 0.474 \\
1995 & 0.139 & 2.456 & 3.104 & 0.501 \\
1996 & 0.137 & 2.489 & 3.164 & 0.515 \\
1997 & 0.133 & 2.581 & 3.250 & 0.535 \\
1998 & 0.130 & 2.615 & 3.385 & 0.567 \\
1999 & 0.126 & 2.663 & 3.559 & 0.609 \\
2000 & 0.125 & 2.615 & 3.654 & 0.632 \\
2001 & 0.123 & 2.634 & 3.780 & 0.663 \\
2002 & 0.120 & 2.726 & 3.902 & 0.692 \\
2003 & 0.117 & 2.803 & 3.993 & 0.714 \\
2004 & 0.115 & 2.872 & 4.043 & 0.725 \\
2005 & 0.110 & 2.978 & 4.323 & 0.793 \\
2006 & 0.106 & 3.055 & 4.538 & 0.845
\end{tabular}

As one can see, the Nucl and the BF suggest either veto $[3 ; 2,1,1]$ or dictatorial rule $[1 ; 1,0,0]$ since they cannot distinguish between the two, while the SSI prescribes dictatorial rule. The analysis 
suggests the reinforcement of the representation of domestic water users in the committee. ${ }^{25}$ This is in line with the recent conclusion of the French audit office which has questioned the functioning of the WAs [12]. One of the main critiques is that there is a persistent imbalance in the representation of different categories of water users in the RBCs, with agriculture being regularly favoured by the system (having a "quasi-monopoly", [12]).

\section{$5 \quad$ Policy Relevance and Concluding Remarks}

In this paper, I adapt different tools and techniques from game theory, political science and welfare economics to analyze decision making process within environmental committees. I use data on the six French RBCs in the period 1987-2007 to illustrate the main points. The analysis may be useful for researchers and policy makers seeking to improve the design of the decision making process over environmental issues. In the context of French water policy, this work brings relevant insights to the recent policy debates such as the functioning of the RBCs [12].

One of the main messages is that in deciding on the committee composition and voting rule, the relationship between voting power indices (not just between voting weights), should be the main focus of concern and attention of the negotiating parties. I illustrate this point under binary voting situations using traditional power indices such as the Bz and the SSI. In general, the voting power measured by these indices is not equivalent to voting weights. While the higher number of votes implies the higher power, the relationship is not straightforward. However, as we have seen, for French RBCs the relationship between the voting weights and power is nearly proportional as it is a special case of limit behaviour [23]. Another important message is that often an increases in a member's voting share results in less than a proportional increase in his voting power. Moreover, as we have observed for the Adour-Garonne RBC, an increase in a member's voting share may lead to a decrease in his voting power. Additionally, and as the analysis demonstrates, when some decision makers act as a block the voting power of the block is not necessarily a sum of the individual powers.

I also show how to proceed with the analysis of the distributive voting situations, such as funding local projects through subsidies. I apply the SSI which is well known in this context, as well as two other power measures - the Nucl and the BF measure, which are less known but suitable in this context. One of the main conclusions of this exercise is that often these indices give the same predictions.

\footnotetext{
${ }^{25}$ One may argue that domestic water users should also include unemployed and retired people. However, the gap in shares then becomes even bigger, and the conclusion does not change.
} 
In Section 4, I employ different power measures to address an important issue regarding the fair representation of different interests within a committee (e.g., different water user categories in the RBCs). First, I provide a descriptive analysis of the problem and a methodology for the design of an optimal decision rule in the context of RBCs. The use of the technique is illustrated by a simple computation exercise for the Adour-Garonne river basin. The main policy implication of the exercise, which is in line with the conclusion of the French audit office, is that up to now the committee composition and/or the voting rule has been biased against domestic water users. One of the possibilities to improve the situation would be to increase the number of domestic users in the RBCs (and possibly other representatives who vote in line with the domestic water users). Obviously, one should be careful with the conclusions as they are based on a set of assumptions concerning the functioning of the committees and the preferences of their members. For example, when considering the distributive voting situations, we have assumed that the representatives of the administration act on behalf of a particular water users' group. It is not straightforward to collect direct evidence supporting that assumption. A careful examination of the proceedings reproducing the synthesis of the debates within the committee would be a first step in that direction.

\section{Acknowledgements}

I am grateful to Alban Thomas for sharing the data on the six French river basin committees over the period 1987-2007. I also thank Stefan Ambec, Michel Le Breton, Christoph Rheinberger, François Salanié, Alban Thomas, the associate editor and two anonymous referees for their helpful comments. The research leading to these results has received funding from the People Programme (Marie Curie Actions) of the European Union's Seventh Framework Programme FP7/2007-2013/ under REA grant agreement number 609642 .

\section{References}

[1] Algaba, E. Bilbao, J.M and J.R. Fernández (2007) "The Distribution of Power in the European Constitution", European Journal of Operational Research 176, 1752-1766.

[2] Alon, N. and P.H. Edelman (2010). "The Inverse Banzhaf Problem", Social Choice and Welfare $34,371-377$.

[3] Banks, J.S. and J. Duggan (2000). "A Bargaining Model of Collective Choice", American Political Science Review 94, 73-88. 
[4] Banzhaf, J.F. III. (1965). "Weighted Voting Doesn't Work: A Mathematical Analysis", Rutgers Law Review 19, 317-343.

[5] Banzhaf, J.F. III. (1968). "One Man 3.312 Votes: A Mathematical Analysis of the Electoral College", Villanova Law Review 13, 304-332.

[6] Barberà, S. and M.O. Jackson (2006). "On the Weights of Nations : Assigning Voting Weights in a Heterogeneous Union", Journal of Political Economy 114, 317-339.

[7] Baron, D. P. and J. A. Ferejohn (1989) "Bargaining in Legislatures", American Political Science Review 83, 1181-1206.

[8] Barr, J. and F Passarelli (2009). "Who Has the Power in the EU?", Mathematical Social Sciences 57 (3), 339-366.

[9] Beisbart, C., Bovens, L. and S. Hartmann (2005). "A Utilitarian Assessment of Alternative Decision Rules in the Council of Ministers", European Union Politics 6, 395-418.

[10] Beisbart, C. and S. Hartmann (2010). "Welfarist Evaluations of Decision Rules under Interstate Utility Dependencies", Social Choice and Welfare 34, 315-344.

[11] Berg, S. (1990) "The Probability of Casting a Decisive Vote: The Effect of a Caucus, Public Choice 64, 73-92.

[12] Cour des Comptes. Rapport Public Annuel 2015, https://www.ccomptes.fr/ (accessed August 2015).

[13] Eraslan, H. (2002). "Uniqueness of Stationary Equilibrium Payoffs in the Baron-Ferejohn Model", Journal of Economic Theory 103, 11-30.

[14] Felsenthal, D. S. and M. Machover (1998). The Measurement of Voting Power. Theory and Practice, Problems and Paradoxes, Cheltenham: Edward Elgar.

[15] Felsenthal, D. S. and M. Machover (2001). "The Treaty of Nice and Qualified Majority Voting", Social Choice and Welfare 18, 431-464.

[16] Felsenthal, D. S. and M. Machover (2004). "Analysis of QM Rules in the Draft Constitution for Europe Proposed by the European Convention, 2003", Social Choice and Welfare 23, 1-25.

[17] Garcia-Valinas, M. and V. Zaporozhets (2015). "Key Drivers of the EU Budget Allocation: Does Power Matter?", TSE Working Paper TSE-548. 
[18] Goodhue, R. E., Rausser, G. C., Simon, L. K. and S. Thoyer (2008). "Negotiating Over the Allocation of Water Resources" in Game Theory and Policymaking in Natural Resources and the Environment ed. by A. Dinar, J. Albiac and J. Sánchez-Soriano, pp. 132-154.

[19] Kirsch, W. and J. Langner (2011). "Invariably Suboptimal: An Attempt to Improve the Voting Rules of the Treaties of Nice and Lisbon", Journal of Common Market Studies 49(6), 1317-1338.

[20] Kurz, S. (2014). "The Inverse Problem for Power Distributions in Committees", arXiv preprint 1402.0988, 46 pp.

[21] Laruelle, A. and F. Valenciano (2008). Voting and Collective Decision Making, Cambridge University Press.

[22] Laruelle, A. and M. Widgrén (1998). "Is the Allocation of Voting Power Among the EU States Fair?", Public Choice 94, 317-339.

[23] Lindner, I., and M. Machover, (2004). "LS Penrose's Limit Theorem: Proof of Some Special Cases", Mathematical Social Sciences 47(1), 37-49.

[24] Leech, D. and R. Leech (2009). "Reforming IMF and World Bank Governance: In Search of Simplicity, Transparency and Democratic Legitimacy in the Voting Rules", Warwick Economic Research Papers 914.

[25] Le Breton, M., M. Montero, and V. Zaporozhets (2012). "Voting Power in the EU Council of Ministers and Fair Decision Making in Distributive Politics", Mathematical Social Sciences 63, $159-173$.

[26] Maschler, M., B. Peleg, and L. Shapley (1979). "Geometric Properties of the Kernel, Nucleolus, and Related Solution Concepts", Mathematics of Operations Research 4 (4), 303-338.

[27] Maschler, M., E. Solan, and S. Zamir (2013). Game Theory. Cambridge UniversityPress.

[28] Miller, N. R. (2013). "A Priori Voting Power and the US Electoral College": in Power, Voting and Voting Power: 30 Years After, ed. by M. Holler and H. Nurmi, Springer, pp. 411-442.

[29] Montero, M. (2006). "Noncooperative Foundations of the Nucleolus in Majority Games", Games and Economic Behavior 54, 380-397.

[30] Montero, M. (2007). "The Paradox of New Members in the Council of Ministers: A Noncooperative Approach", CeDEx Discussion Paper No. 2007-12. 
[31] Montero, M. (2013). "On the Nucleolus as a Power Index": in Power, Voting and Voting Power: 30 Years After, ed. by M. Holler and H. Nurmi, Springer, pp. 283-299.

[32] Napel, S. and M. Widgrén (2006). "The Inter-Institutional Distribution of Power in EU Codecision", Social Choice and Welfare 27, 129-154.

[33] Napel, S. and M. Widgrén (2011). "Strategic versus Non-Strategic Voting Power in the EU Council of Ministers: The Consultation Procedure", Social Choice and Welfare 37, 511-541.

[34] Penrose, L. S. (1946). "The Elementary Statistics of Majority Voting", Journal of the Royal Statistical Society 109, 53-57.

[35] Schmeidler, D. (1669). "The Nucleolus of a Characteristic Function Game", SIAM Journal on Applied Mathematics 17, 1163-1170.

[36] Shapley, L.S. and M. Shubik (1954). "A Method for Evaluating the Distribution of Power in a Committee System", American Political Science Review 48, 787-792.

[37] Straffin, P.D. (1977). "Homogeneity, Independence, and Power Indices", Public Choice 30, 107118. 


\section{Appendix}

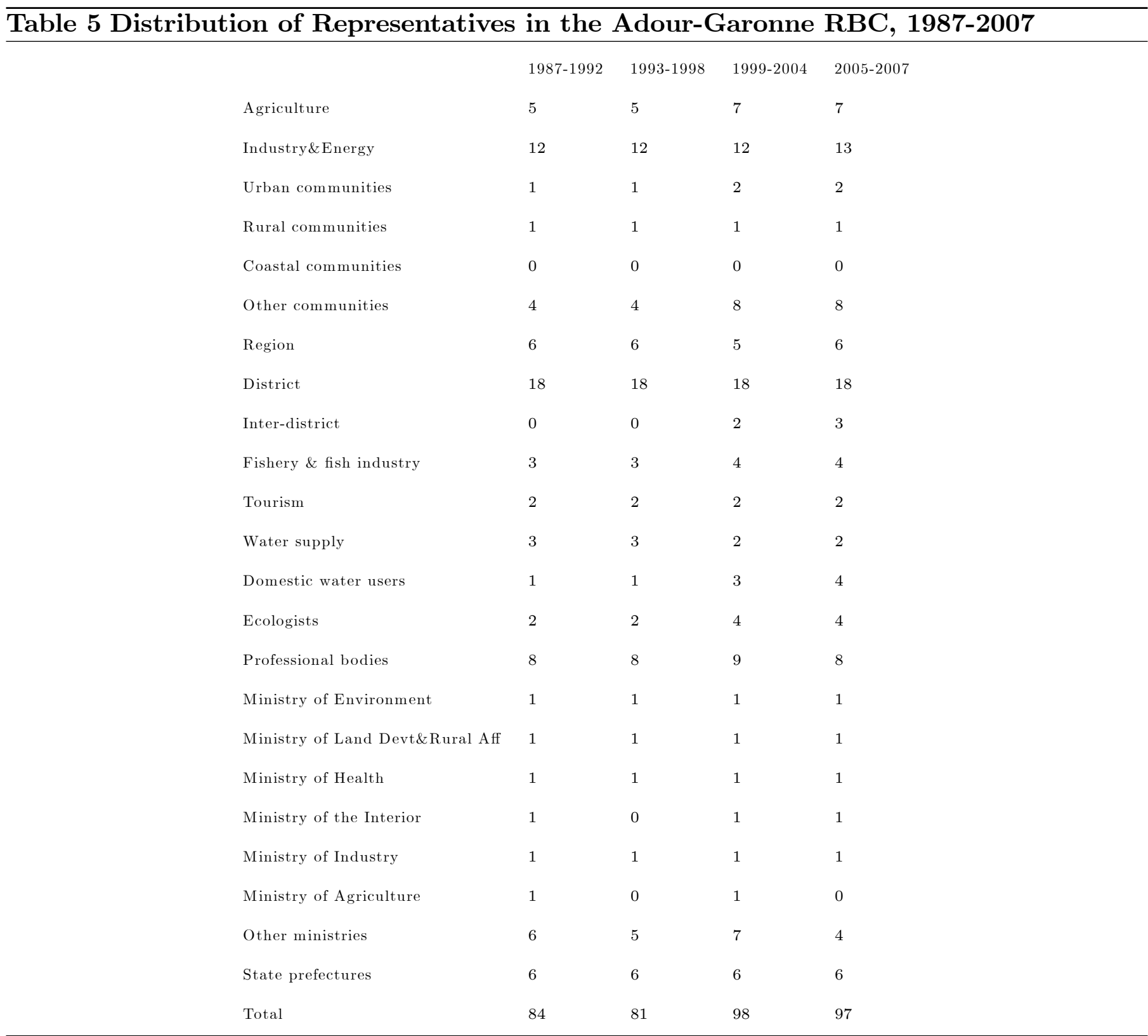




\section{Table 6 Power Values for the Adour-Garonne RBC, 1987-2007}

\begin{tabular}{|c|c|c|c|c|c|c|c|c|c|c|c|c|}
\hline & \multicolumn{3}{|c|}{ 1987-1992 } & \multicolumn{3}{|c|}{ 1993-1998 } & \multicolumn{3}{|c|}{ 1999-2004 } & \multicolumn{3}{|c|}{$2005-2007$} \\
\hline & $\mathbf{q}_{i} / \mathbf{n}$ & $\mathrm{Bz}$ & SSI & $\mathbf{q}_{i} / \mathbf{n}$ & $\mathrm{Bz}$ & SSI & $\mathbf{q}_{i} / \mathbf{n}$ & $\mathrm{Bz}$ & SSI & $\mathbf{q}_{i} / \mathbf{n}$ & $\mathrm{Bz}$ & SSI \\
\hline Agriculture & 0.060 & 0.057 & 0.056 & 0.062 & 0.059 & 0.058 & 0.071 & 0.069 & 0.069 & 0.072 & 0.070 & 0.070 \\
\hline Industry\&Energy & 0.143 & 0.135 & 0.146 & 0.148 & 0.139 & 0.151 & 0.122 & 0.121 & 0.126 & 0.134 & 0.133 & 0.140 \\
\hline Urban communities & 0.012 & 0.011 & 0.011 & 0.012 & 0.012 & 0.011 & 0.020 & 0.019 & 0.019 & 0.021 & 0.020 & 0.019 \\
\hline Rural communities & 0.012 & 0.011 & 0.011 & 0.012 & 0.012 & 0.011 & 0.010 & 0.010 & 0.009 & 0.010 & 0.010 & 0.009 \\
\hline Coastal communities & 0 & 0 & 0 & 0 & 0 & 0 & 0 & 0 & 0 & 0 & 0 & 0 \\
\hline Other communities & 0.048 & 0.045 & 0.045 & 0.049 & 0.047 & 0.046 & 0.082 & 0.079 & 0.080 & 0.082 & 0.080 & 0.080 \\
\hline Region & 0.071 & 0.068 & 0.068 & 0.074 & 0.071 & 0.070 & 0.051 & 0.049 & 0.049 & 0.062 & 0.060 & 0.059 \\
\hline District & 0.214 & 0.253 & 0.248 & 0.222 & 0.262 & 0.258 & 0.184 & 0.210 & 0.210 & 0.186 & 0.211 & 0.212 \\
\hline Inter-district & 0 & 0 & 0 & 0 & 0 & 0 & 0.020 & 0.019 & 0.019 & 0.031 & 0.030 & 0.029 \\
\hline Fishery \& fish industry & 0.036 & 0.034 & 0.033 & 0.037 & 0.035 & 0.034 & 0.041 & 0.039 & 0.039 & 0.041 & 0.040 & 0.039 \\
\hline Tourism & 0.024 & 0.022 & 0.022 & 0.025 & 0.023 & 0.022 & 0.020 & 0.019 & 0.019 & 0.021 & 0.020 & 0.019 \\
\hline Water supply industry & 0.036 & 0.034 & 0.033 & 0.037 & 0.035 & 0.034 & 0.020 & 0.019 & 0.019 & 0.021 & 0.020 & 0.019 \\
\hline Domestic water users & 0.012 & 0.011 & 0.011 & 0.012 & 0.012 & 0.012 & 0.031 & 0.029 & 0.029 & 0.041 & 0.040 & 0.039 \\
\hline Ecologists & 0.024 & 0.022 & 0.022 & 0.025 & 0.023 & 0.022 & 0.041 & 0.039 & 0.039 & 0.041 & 0.040 & 0.039 \\
\hline Professional bodies & 0.095 & 0.093 & 0.093 & 0.099 & 0.096 & 0.110 & 0.092 & 0.090 & 0.091 & 0.082 & 0.080 & 0.081 \\
\hline Ministry of Environment & 0.012 & 0.011 & 0.011 & 0.012 & 0.012 & 0.011 & 0.010 & 0.010 & 0.009 & 0.010 & 0.010 & 0.009 \\
\hline Ministry of Land Devt\&Rural Aff & 0.012 & 0.011 & 0.011 & 0.012 & 0.012 & 0.011 & 0.010 & 0.010 & 0.009 & 0.010 & 0.010 & 0.009 \\
\hline Ministry of Health & 0.012 & 0.011 & 0.011 & 0.012 & 0.012 & 0.011 & 0.010 & 0.010 & 0.009 & 0.010 & 0.010 & 0.009 \\
\hline Ministry of the Interior & 0.012 & 0.011 & 0.011 & 0 & 0 & 0 & 0.010 & 0.010 & 0.009 & 0.010 & 0.010 & 0.009 \\
\hline Ministry of Industry & 0.012 & 0.011 & 0.011 & 0.012 & 0.012 & 0.011 & 0.010 & 0.010 & 0.009 & 0.010 & 0.010 & 0.009 \\
\hline Ministry of Agriculture & 0.012 & 0.011 & 0.011 & 0 & 0 & 0 & 0.010 & 0.010 & 0.009 & 0 & 0 & 0 \\
\hline Other ministries & 0.071 & 0.068 & 0.068 & 0.062 & 0.059 & 0.058 & 0.071 & 0.069 & 0.069 & 0.041 & 0.040 & 0.039 \\
\hline State prefectures & 0.071 & 0.068 & 0.068 & 0.074 & 0.071 & 0.070 & 0.061 & 0.059 & 0.059 & 0.062 & 0.060 & 0.059 \\
\hline
\end{tabular}




\begin{tabular}{|c|c|c|c|c|c|c|c|c|c|c|c|c|}
\hline \multirow{3}{*}{ Table 7 Power Value } & \multirow{3}{*}{$\begin{array}{l}\text { for } \\
\mathbf{q}_{i} / \mathbf{n}\end{array}$} & \multirow{2}{*}{\multicolumn{3}{|c|}{$\begin{array}{l}\text { Adour-Garonne } \\
1987-1992\end{array}$}} & \multicolumn{6}{|c|}{ RBC (11 groups), 1987-2007 } & \multirow{2}{*}{\multicolumn{2}{|c|}{$2005-2007$}} \\
\hline & & & & & \multicolumn{2}{|c|}{$1993-1998$} & \multicolumn{3}{|c|}{$1999-2004$} & \multirow[b]{2}{*}{$\mathbf{q}_{i} / \mathbf{n}$} & & \\
\hline & & $\mathbf{B z}$ & SSI & $\mathbf{q}_{i} / \mathbf{n}$ & $\mathrm{Bz}$ & SSI & $\mathbf{q}_{i} / \mathbf{n}$ & $\mathrm{Bz}$ & SSI & & \multirow{2}{*}{$\begin{array}{l}\mathrm{Bz} \\
0.078\end{array}$} & \multirow{2}{*}{$\begin{array}{l}\text { SSI } \\
0.076\end{array}$} \\
\hline Agriculture & 0.083 & 0.074 & 0.074 & 0.074 & 0.066 & 0.065 & 0.092 & 0.089 & 0.086 & 0.082 & & \\
\hline Industry & 0.143 & 0.135 & 0.138 & 0.148 & 0.139 & 0.144 & 0.122 & 0.107 & 0.103 & 0.134 & 0.138 & 0.131 \\
\hline Urban communities & 0.012 & 0.009 & 0.008 & 0.012 & 0.008 & 0.007 & 0.020 & 0.018 & 0.015 & 0.021 & 0.021 & 0.020 \\
\hline Rural communities & 0.012 & 0.009 & 0.008 & 0.012 & 0.008 & 0.007 & 0.010 & 0.009 & 0.008 & 0.010 & 0.011 & 0.012 \\
\hline Environmental ass. & 0.167 & 0.147 & 0.156 & 0.160 & 0.141 & 0.150 & 0.184 & 0.173 & 0.188 & 0.196 & 0.176 & 0.187 \\
\hline Other communities & 0.048 & 0.048 & 0.044 & 0.049 & 0.054 & 0.051 & 0.082 & 0.078 & 0.076 & 0.082 & 0.078 & 0.076 \\
\hline Districts and Regions & 0.286 & 0.356 & 0.353 & 0.296 & 0.373 & 0.369 & 0.255 & 0.297 & 0.302 & 0.278 & 0.323 & 0.323 \\
\hline Ministry of Industry & 0.012 & 0.009 & 0.008 & 0.012 & 0.008 & 0.007 & 0.010 & 0.009 & 0.008 & 0.010 & 0.011 & 0.012 \\
\hline Professional bodies & 0.095 & 0.082 & 0.081 & 0.099 & 0.079 & 0.077 & 0.092 & 0.089 & 0.086 & 0.082 & 0.078 & 0.076 \\
\hline Other ministries & 0.071 & 0.065 & 0.065 & 0.062 & 0.058 & 0.059 & 0.071 & 0.070 & 0.069 & 0.041 & 0.031 & 0.033 \\
\hline State prefectures & 0.071 & 0.065 & 0.065 & 0.074 & 0.066 & 0.065 & 0.061 & 0.062 & 0.059 & 0.062 & 0.055 & 0.055 \\
\hline
\end{tabular}

1. Farmers (including representatives of the Ministries of Agriculture, Land Development and Rural Affairs);

2. Industry (including Energy);

3. Urban communities (domestic water users);

4. Rural communities;

5. Environmental associations (including fishery, water suppliers, tourism, Ministries of Health, Environment, the Interior, associations of domestic water users);
6. Other communities;
7. Districts and Regions;
8. Ministry of Industry;
9. Professional bodies;
10. Other ministries;
11. State prefectures. 
Table 8 Population Shares for Industrial, Agricultural and Residential Water Users in the Adour-Garonne River Basin, 1989-2006

\begin{tabular}{l|rrr}
\hline & Industry & Agriculture & Domestic \\
1989 & 0.088 & 0.053 & 0.859 \\
1990 & 0.088 & 0.051 & 0.861 \\
1991 & 0.086 & 0.050 & 0.865 \\
1992 & 0.083 & 0.049 & 0.868 \\
1993 & 0.081 & 0.047 & 0.872 \\
1994 & 0.079 & 0.045 & 0.876 \\
1995 & 0.079 & 0.043 & 0.878 \\
1996 & 0.078 & 0.043 & 0.879 \\
1997 & 0.076 & 0.042 & 0.882 \\
1998 & 0.075 & 0.040 & 0.885 \\
1999 & 0.074 & 0.038 & 0.888 \\
2000 & 0.075 & 0.036 & 0.889 \\
2001 & 0.075 & 0.035 & 0.890 \\
2002 & 0.073 & 0.034 & 0.893 \\
2003 & 0.071 & 0.034 & 0.895 \\
2004 & 0.070 & 0.033 & 0.897 \\
2005 & 0.068 & 0.031 & 0.901 \\
2006 & 0.066 & 0.030 & 0.904 \\
\hline
\end{tabular}

